\title{
ТСМ \\ An inconvenient source? Attributes of science documentaries and their effects on information-related behavioral intentions
}

\section{Sara K. Yeo, Andrew R. Binder, Michael F. Dahlstrom and Dominique Brossard}

\begin{abstract}
We investigate the impact of a science documentary on individuals' intention to engage in information-related behaviors by experimentally testing the effects of source type (scientist, politician, or anonymous source) and communication setting (interview or lecture) using a manipulated clip from the documentary, An Inconvenient Truth. Our results indicate that, compared to anonymous sources, use of authoritative ones result in greater intention to engage in some information-related behaviors. Additionally, our results suggest that increased intentions to engage in exchanging information can be attributed to negative affect induced by the clip featuring a politician. Implications for documentary films and science communication are discussed.
\end{abstract}

Keywords

Environmental communication; Science and media; Science communication: theory and models

DOI

https://doi.org/10.22323/2.17020207

Documentary films have long been used as tools of public engagement on a range of relevant issues in the United States. Political documentary films have received prestigious recognition (e.g., Citizenfour received the Academy Award for Best Documentary Feature in 2015) and been profitable (e.g., Fahrenheit 9/11 earned \$222.4 million in the box office, 2016: Obama's America earned \$33.4 million in the box office). Other documentaries have focused on issues related to science, including the launch of the Large Hadron Collider (e.g., Particle Fever) and environmental sustainability challenges related to animal agriculture (e.g., Cowspiracy), albeit with less widespread success and recognition relative to their political counterparts.

The science documentary, An Inconvenient Truth, was released in 2006 and it and its sequel remain unique among documentary feature films. An Inconvenient Truth was both successful at the box office, grossing \$24 million in the United States, and garnering numerous awards in the same year. Interestingly, some have likened the narrative in the documentary to that of a "conspiracy thriller" [Bartlett, 2009, p. 6]. In 2017, a sequel about climate politics, An Inconvenient Sequel: Truth to Power, was released. While the sequel is overtly political, the original film focuses on the 
scientific evidence for global warming. Yet, it is implicitly political through its featured speaker, former Democratic Vice President Al Gore. An Inconvenient Truth frames global warming as an imminent global catastrophe [Nisbet, 2009] instead of de-emphasizing the phenomenon as a temporally and geographically remote environmental risk with intangible effects. Moreover, it features direct calls to seek information about the issue and engage in environmentally-friendly behaviors.

Though a large body of scholarship exists around the cultivation effects of television viewing [Gerbner et al., 1982; for examples of scholarship on cultivation effects, see Mutz and Nir, 2010; Stroud, 2007; Valenzuela and Brandão, 2015], for documentaries aimed at public engagement such as An Inconvenient Truth, it is worth asking about their effects. While the impacts and mechanisms of narrative persuasion in entertainment media are widely studied using models such as the extended-elaboration likelihood [Slater and Rouner, 2002; Slater, Rouner and Long, 2006] and entertainment overcoming resistance models [Moyer-Gusé, 2008;

Moyer-Gusé, Jain and Chung, 2012; Moyer-Gusé and Nabi, 2010], investigations of the potential media effects of documentary feature films are scant and there is an even greater paucity with regard to science documentaries. A few studies have analyzed survey data [Leiserowitz, 2004; Lin, 2013; Löfgren and Nordblom, 2010; Stroud, 2007] and conducted secondary data analysis [Jacobsen, 2011] to elucidate the effects of An Inconvenient Truth, while others have speculated about the usefulness of climate films [Manzo, 2017].

Using An Inconvenient Truth as a case study, the present work is an initial attempt to tackle the question of persuasiveness of a science documentary film using an experimental design. These types of films, like any other mediated form of communication, feature certain attributes that may distinguish them from other types of media [Eveland, 2003]. We focus on two such attributes: (i) the speaker featured in the film; and (ii) the context in which that speaker presents information. This preliminary study contributes to research on science documentaries, which have largely been overlooked in existing science communication scholarship. Because our theoretical framework is grounded in the persuasion literature, we begin by outlining three relevant concepts: behavioral intentions, source attributes as heuristic cues, and the potential mediating role of affect.

Research on persuasion focuses generally on three types of outcomes: cognitive, attitudinal, and behavioral. Behavioral outcomes - especially those related to disseminating information - are relevant to documentary films for two reasons. First, on a practical, financial level, film producers are interested in profit. They pursue this goal through advertising (mass communication), but they likely expect word-of-mouth (interpersonal communication) efforts to bring people to movie theaters as well. Second, on a normative level, documentary filmmakers are interested in raising the public's consciousness of topical issues, with a goal of societal-level changes in public engagement. This was particularly true for the producers of An Inconvenient Truth [Little, 2007].

In persuasion research, the theory of reasoned action focuses on behavior and provides an interpretive framework for the conceptualization of our dependent 
variables. This framework is a "theory of the immediately proximal causes of volitional behavior" [Eagly and Chaiken, 1993, p. 173]. While our study is not an explicit test of this model, the three key elements of the Theory of Reasoned Action inform our choice of outcome variables and potential influences on those behaviors. ${ }^{1}$ Most importantly, the model predicts behavioral intentions rather than overt behavior, which entails certain assumptions. In their original formulation of the model, Ajzen and Fishbein [1970] argued that the strong correlation between behavior and intention is contingent on the time interval between measurement of intention and opportunity to engage in behavior. Consequently, "in attempting to predict behavior it is therefore the experimenter's responsibility to insure the conditions under which BI [behavioral intention] is measured will be maximally conducive to a high correlation between BI and B [behavior]" [Ajzen and Fishbein, 1970, p. 469]. Considering this caveat, our study focuses on behavioral intentions related to three behaviors that would be relatively easy to perform immediately following exposure to a documentary film; these are described below.

Conceptualizing information-related behavioral intentions. Rather than reviewing the concept of behavioral intention itself (which has received abundant attention in the persuasion literature; see Ajzen [1991]; Ajzen and Fishbein [1970]), we outline a conceptualization of outcomes that incorporate two characteristics. First, they are related to the information presented in a documentary film, and second, they vary in levels of effort required for engagement. The easiest of these behaviors focuses on an individual's efforts to gather further information about the documentary's content. We term this outcome information gathering and differentiate this behavior from information seeking, which is often synonymous with learning [e.g., Griffin et al., 2008]. We do so because our focus is on the utility of information as a resource, regardless of whether that information is subsequently used or integrated into existing knowledge structures.

The other two behaviors focus on interpersonal discussion, which can be a direct result of viewing a documentary film [e.g., Rojas et al., 2005; Stroud, 2007]. The second outcome in this study is a typical form of discussion engagement, specifically discussion about information featured in the film. This type of discussion corresponds to the word-of-mouth publicity sought by film producers. Such discussions primarily function to raise awareness, and we conceptualize them as unrelated to specific goals. We label this outcome information exchanging. The third outcome builds on information exchanging by specifying persuasion as a goal of discussion engagement. It focuses on the potential for viewers of the film to use information presented to persuade discussion partners toward a specific point of view. We refer to this outcome as information promoting.

In the Theory of Reasoned Action, two key predictors of behavioral intentions are attitudes toward the behavior and subjective normative beliefs. The latter concept is defined as "the individual's perception of the behaviors expected of him by relevant or significant others" [Ajzen and Fishbein, 1970, p. 467]. It is likely that

\footnotetext{
${ }^{1}$ The theory of planned behavior was proposed as an improvement upon the theory of reasoned action. The former addresses the volitional component of behavior and takes into account various difficulties an individual may encounter in performing a given behavior [Ajzen, 1991]. For reasons that will become clear, we focus on behaviors that are relatively easy to perform following the viewing of our experimental stimulus. Therefore, we rely on the more parsimonious theory of reasoned action to inform our investigation.
} 
exposure to communication has the potential to impact both attitudes toward the behavior and subjective normative beliefs and, consequently, our dependent variables. We therefore provide an overview of the key attributes of documentary films that could influence these factors.

\section{Source attributes as heuristic cues in documentary films}

Information processing models are central to our preliminary study on the effect of science documentaries on behavioral intentions. In general, information processing models are dual process ones. They posit two routes of processing; one that is slower, more cognitively effortful, and deliberate, and another that is faster, requires less cognitive effort, and uses mental shortcuts or heuristic cues [Cacioppo et al., 1986; Chaiken, Liberman and Eagly, 1989; Kahneman, 2011; Kahneman, Slovic and Tversky, 1982; Petty and Cacioppo, 1986; Tversky and Kahneman, 1974]. While models such as the Elaboration Likelihood Model (ELM) [Cacioppo et al., 1986; Petty and Cacioppo, 1986], the Heuristic-Systematic Model (HSM) [Chaiken, Liberman and Eagly, 1989], and the two-system perspective [Stanovich and West, 2000; Tversky and Kahneman, 1974] differ in details, their dual process natures are consistent. Here, we are primarily concerned with the faster mode of processing that uses heuristic cues and specifically seek to test the effects of various attributes of the information source in a science documentary on individual behavioral intentions.

There are several heuristic attributes that reflect variation between documentary films and differentiate these films from other forms of media. If we adopt a "mix of attributes" approach [Eveland, 2003], documentary films can be readily distinguished from other forms of media by their long-form narrative structure (or organization), presentation of alpha-numeric textual information, and - perhaps most evidently - their content. But, different documentary films can also be distinguished from one another through channel attributes, i.e., differences in audio and/or visual presentation [Eveland, 2003]. In the present work, we explore such differences by manipulating the source of the information.

Conceptualizing source types. Source type can have a direct impact on viewers and we focus on two dimensions in the present work. First, documentary films often feature commentary by well-spoken and highly educated sources, who speak authoritatively on a topic. Second, these films often feature a narrator, who links images and textual information with a broader narrative storyline. The narrator often remains unidentified. In the rare case where he or she is identified, it is typically only by name. Our first conceptual distinction, therefore, is between authoritative, anonymous, and unidentified sources.

Authoritative sources can be further divided according to certain salient attributes. An authoritative source may be an expert in a certain subject domain because of their profession. Alternatively, an authoritative source may be perceived as such due to notoriety or celebrity [Biswas, Biswas and Das, 2006]. A meta-analysis of source effects in communication found that expert-nonexpert manipulations had stronger effects on persuasion relative to other types of source manipulations [Wilson and Sherrell, 1993]. In the present work, we compare a celebrity with an expert. Similar to its conceptualization in advertising scholarship [McCracken, 
1989], we define celebrity as an individual who uses public recognition to champion a cause. Experts, on the other hand, are individuals who are highly knowledgeable about a specific topic [Horai, Naccari and Fatoullah, 1974] and their expertise accrues from education and experience [Birnbaum and Stegner, 1979]. Some studies suggest that celebrities tend to be more persuasive along dimensions of believability and likability [Till and Shimp, 1998], while others highlight celebrity endorsements as heuristic cues in persuasion [Petty, Cacioppo and Schumann, 1983]. More recent work in the context of dietary supplement advertisements suggest that respondents preferred celebrity endorsements over expert ones [Wu et al., 2012].

In the context of climate change, we focus on two types of common authoritative sources, a scientist and a politician. This distinction is not trivial; a content analysis revealed that not only are scientists and politicians often featured in news stories as sources of information about global warming, they also tend to play different roles in presenting that information [Trumbo, 1996]. For the reasons outlined above, we assume scientists will be viewed as more expert than celebrity, while politicians will be viewed more as celebrity than expert.

Conceptualizing message settings. The second focus of our investigation is the context of the communication situation in which the source of the information is situated [Eagly and Chaiken, 1993]. Here, we define two types of settings, a lecture and an interview. Watching a lecture, of course, entails viewing a speaker attempting to persuade other people. An interview, conversely, entails viewing a source attempting to persuade a single other person (the interviewer), who may or may not be visible to the viewer. One crucial distinction between these contexts is the presence of other people. Past experimental research on effects of viewing daytime talk shows and entertainment programs has demonstrated that the presence of an audience can strongly influence perceptions of viewers [Nabi and Hendriks, 2003; Olson, 1992].

A second aspect of the setting, related to the first, pertains to the source's control over information presented. ${ }^{2}$ Source control has been important in advertising research, which defines successful "hybrid messages" as those which combine a credible source with his or her substantive control over a message's content [Balasubramanian, 1994]. In an interview setting, the authority of the source has the potential to be contested by the interviewer [Ekström, 2001]. For example, the lack of control of interviewees over content has garnered media attention of scientists' objections to the intelligent-design film Expelled [Dean, 2007]. In contrast, with the context of a filmed lecture, there is no such potential for contestation; control over content of the interview lies in the hands of the source. While the distinction related to control between interview and lecture setting may not be explicitly recognized by an audience, we propose that these implicit differences may have some impact on the way that viewers process the information presented.

\footnotetext{
${ }^{2}$ This should not be confused with "control" as a media attribute, i.e., the amount of control a user has over the medium [Eveland, 2003].
} 


\section{Hypotheses and research questions}

Our review of the literature points to several plausible relationships related to watching a documentary film about climate change and intentions to engage in various information-related behaviors. We first put forth the following hypotheses regarding source type:

H1a: Respondents are more likely to engage in information gathering when information about climate change is presented by an authoritative source in a documentary film, compared to an anonymous or unidentified source.

H1b: Respondents are more likely to engage in information exchanging when information about climate change is presented by an authoritative source in a documentary film, compared to an anonymous or unidentified source.

H1c: Respondents are more likely to engage in information-promoting behaviors when information about climate change is presented by an authoritative source in a documentary film, compared to an anonymous or unidentified source.

The current debate over global warming features arguments coming from a variety of sources, notably scientists and politicians. Because we have no expectations about how these two types of authoritative sources might affect our outcomes, we pose the following question:

$R Q 1:$ How does the type of authoritative source (scientist versus politician) influence respondents' intentions to gather, exchange, and promote information?

Finally, we suspect that the setting of a documentary film may influence how audiences react to it. Most climate change information in An Inconvenient Truth is presented in a lecture-type format. Our second research question focuses on the ability of this format, compared to the traditional interview format, to influence respondents' intentions to perform information-related behaviors. Formally, we ask:

$R Q 2:$ How does the communication setting (lecture versus interview) in which the information is presented influence respondents' intentions to perform information-related behaviors?

\section{Intervening role of negative affect}

In addition to effects due to source type, it is also important to consider viewers' emotional reactions. Past research has demonstrated how affect influences individual responses to a variety of mediated content, including advertising [Bower, 2001], public service announcements [Dillard and Peck, 2000], news broadcasts [Newhagen, 1998], and films [Pouliot and Cowen, 2007]. With the focus of the present study on information related to global warming, which is typically 
discussed in terms of risk, affect is likely to play a role in shaping viewers' behavioral intentions.

The role of affect in influencing persuasion outcomes has mainly been explored in information processing models. Studies have demonstrated that mental shortcuts based on affective responses can explain risk and benefit judgments related to a hazard or issue. Comparing affective and cognitive approaches to information processing, scholars have identified affect as an integral component of judgment and decision making [Finucane et al., 2000; George and Dane, 2016; Lerner et al., 2015]. Indeed, the affect heuristic has been placed among other commonly used mental shortcuts from the literature on decision making [Finucane et al., 2000], including availability, representativeness, and anchoring and adjusting heuristics [Tversky and Kahneman, 1974]. Research has shown that negative affective responses, such as anger, can lead individuals to report both high levels of information insufficiency and intentions to seek out further information on a given topic [Griffin et al., 2008]. Other studies have shown that messages that induce fear can discourage individuals from engagement with climate change $\left[\mathrm{O}^{\prime} \mathrm{Neill}\right.$ and Nicholson-Cole, 2009]. These outcomes are particularly relevant to this study given our focus on information-related behavioral outcomes.

Scholarship on affect highlights its potential as a factor influencing information-related behaviors in the context of climate change. People tend to be cognitive misers [Fiske and Taylor, 1991] who rely on heuristic cues in decision making, as in the heuristic-systematic or elaboration likelihood models of persuasion [Chaiken, 1980; Petty and Cacioppo, 1986]. In addition, the framing of information about science, especially the "Pandora's box" frame that evokes catastrophic consequences for humanity, can impact emotional reactions to scientific information [Nisbet and Scheufele, 2007]. Recently, scholars have argued that such approaches to presenting information about climate change increase salience but may ultimately be counter-productive for engendering long-term public engagement [O'Neill and Nicholson-Cole, 2009].

Our experimental design will not allow us to test for long-term impacts, but we are able to investigate the effects of the content of the film across a variety of contexts. Thus, given the subject matter of An Inconvenient Truth, and its depiction of global warming as an imminent global catastrophe, we expect negative emotions to play a role in influencing viewers' reactions to the film. Moreover, we expect these affective responses to play a significantly greater role in influencing behavioral intentions than the source and context effects outlined earlier. For the purposes of this study, our conceptualization of affect aligns with that of Slovic and colleagues [2004; 2002]. In other words, affect refers to "specific quality of "goodness" or "badness" (i) experienced as a feeling state (with or without consciousness) and (ii) demarcating a positive or negative quality of a stimulus" [Slovic et al., 2002, p. 329]. Thus, we propose the following mediation hypothesis:

H2: The effects of source type and communication setting on behavioral intentions related to information are mediated by negative affect induced by watching the documentary film clip. 
This experiment investigates potential influences of a documentary film clip on the adoption of behaviors related to global climate change. Our focus is, first, on the effects of authoritative sources and settings on these behavioral outcomes and, second, on the role of negative affect in mediating those effects. The stimulus was based on the science documentary, An Inconvenient Truth, which discusses the negative effects of global warming. We manipulated the source type and communication context, or setting, in a short clip from this documentary. A total of four versions of the stimulus video were produced. The total length of each video was 3 minutes and 26 seconds, and the audio narration presented in each video was identical (see appendix for transcript). They differed only in the presentation of the source and communication setting.

Treatment 1: Politician lecture. The first version of the stimulus video was produced by editing clips from the original documentary into one short, cohesive segment. The speaker in the documentary was Al Gore, a politician and environmental advocate. Therefore, the first version of the stimulus served as politician (source type) providing environmental information in a lecture hall (context). A name bar identifying the source as "Al Gore, politician and former presidential candidate" was added on screen during the first six seconds of the stimulus video to identify the speaker.

Treatment 2: Scientist lecture. In this version of the stimulus, we re-created Treatment 1 using a professional actor and hired extras. The dialogue from the original documentary remained constant and the visuals were carefully reproduced using the same camera angles, shot lengths, settings, lighting choices, and costumes. All graphics and animations were identical and taken directly from the original documentary. A name bar identified the source in this version as "Howard Matthews, climate scientist from Harvard University" during the first six seconds of the stimulus video. This version served as a scientist (source type) providing environmental information in a lecture hall (context).

Treatment 3: Scientist interview. The third version of the stimulus video again retained the same dialogue but altered the setting to represent a one-on-one interview in an academic office. This change in setting also required an alteration of camera angles, but the shot lengths, costumes, graphics, and animations all remained identical to previous versions. Again, a name bar identified the source in this version as "Howard Matthews, climate scientist from Harvard University" during the first six seconds of the stimulus video. This version served as a scientist (source type) providing environmental information in an interview (context).

Treatment 4: Anonymous narrator. The final version of the stimulus video was narrated by a non-identifiable source and was created by displaying only graphics and animations while the professional actor from the previous two stimuli read the narration. This version contained the same graphics and dialogue as the previous versions. The only modification was in extending the duration of the graphics and animations to obtain the same length of video without adding additional content. 
This version served as an anonymous source and was introduced as a documentary that was broadcast on public television.

Because the experimentally produced video may not have been of same quality as the original documentary, a pilot test was administered to eight participants who rated the similarities of the first (politician lecture) and second (scientist lecture) versions of the stimulus video. While they noted minor differences in background props and lighting, the participants rated both versions to be acceptably similar in both setting and speaker.

\section{Participants and procedure}

Undergraduate students enrolled in various introductory communication courses at two large Midwestern universities in the United States served as participants for this study ( $N=347 ; 73$ percent female; age: $M=19.86, S D=1.58)$. Data were collected over a two-week period in December 2008 via an online experiment accessible from any computer with internet access. It is worth noting that these data were collected eight years after Al Gore played a significant role in American politics. In 2000, when Al Gore was campaigning for the Presidency, the average participant would have been 12 years old.

The experimental design entailed one version of the video stimulus embedded within the online questionnaire. After consenting to participate in a study about media and their opinions toward current issues in the U.S., participants were randomly assigned to one of the four treatment groups. Their first task was to answer a series of pre-test questions including those designed to measure general science knowledge and media use. Then, they viewed the video stimulus. Finally, they were presented with a set of post-test questions designed to measure behavioral intentions.

Time codes were recorded to ensure that the participants watched the entire stimulus video. Those who left the stimulus page before the video was complete were removed; 73 participants were excluded from the analysis resulting in a final sample size of 274 participants.

\section{Measures}

After viewing the stimulus, participants were presented with statements designed to tap their intention to engage in various behaviors related to the information presented in the video. Participants were asked to indicate their likelihood of participating in each behavior on 7-point Likert scales ( $1=$ "Very unlikely", 7 = "Very likely"). We used three relevant behaviors as dependent variables:

(i) gathering additional information about global climate change (information gathering); (ii) exchanging information with others about global climate change (information exchanging); and (iii) intention to persuade others about the importance of global climate change (information promoting).

Information gathering was operationalized by averaging two items asking how likely participants would be to "seek out further information about the topic presented in the video" and "seek out information about the sources presented in the video." 
Responses were coded with agreement represented by larger values $(M=3.63$, $S D=1.54$, Pearson's $r=.689, p \leq .001)$.

The concept of information exchanging was constructed as an average of two items asking respondents how likely they would be to "tell others about the information presented in the video" and "ask others for their opinions regarding the information presented in the video." Responses were coded such that positive values indicated agreement $(M=3.89, S D=1.53$, Pearson's $r=.680, p \leq .001)$.

Information promoting, or the intention to actively persuade others to align their beliefs with the content from the stimulus video, was constructed as an average of two indicators asking how likely participants would be to "try to convince my friends to take the bus or ride a bicycle" and "talk to my friends about the importance of reducing carbon emissions." Responses were coded with agreement high $(M=3.54, S D=1.54$, Pearson's $r=.711, p \leq .001)$.

The mediating variable negative affect was constructed as an average of a set of five items modified from the expanded form of the Positive Affect and Negative Affect Scales (PANAS-X) [Scherer, 2005; Watson, Clark and Tellegen, 1988] asking participants to report the extent to which the video clip made them feel distressed, anxious, fearful, sad, and angry ( $1=$ "Not at all," $7=$ "A lot"). Responses were coded such that higher scores on this index represent greater levels of negative affect $(M=4.20, S D=1.23$, Cronbach's $\alpha=.862)$. Descriptive statistics by treatment for the outcome measures and negative affect are shown in Table 1.

\section{Statistical analysis}

All analyses were conducted using the statistical software, IBM SPSS Statistics. Before addressing our hypotheses and research questions, the distributional shapes of the outcome variables were tested for normality using the Shapiro-Wilk test [Shapiro and Wilk, 1965]. The results of the tests were significant and suggest these data do not meet the assumption of normality (information gathering: $S-W=.945$, $d f=274, p \leq .001$; information exchanging: $S-W=.938, d f=274, p \leq .001$; information promoting: $S-W=.929, d f=274, p \leq .001$ ). Thus, we used a non-parametric procedure, the Kruskal-Wallis test [Kruskal and Wallis, 1952], to conduct pairwise comparisons between treatment groups to address H1a through H1c and our first research question (RQ1).

Since global warming is a polarized issue, we examined bivariate correlations between our outcome variables and political ideology. An index of political ideology was created as an averaged index of two self-reported items, ranging from 1 ("Very liberal") to 7 ("Very conservative"), asking respondents about their social and fiscal issues $(M=3.47, S D=1.32$, Pearson's $r=.575, p \leq .001)$. While information gathering and exchanging were not significantly correlated with political ideology, information promoting was (Pearson's $r=-.233, p \leq .001$ ). To control for the effect of political ideology on information promoting, we regressed the dependent variable on political ideology. The residuals from this regression model were subsequently used as dependent variable for subsequent analyses involving information promoting. Additionally, as 38 percent of our respondents had seen the film, we tested for differences in the dependent variables using Kruskal-Wallis tests with a 
categorical variable asking respondents whether they had seen An Inconvenient Truth $(1=$ "Yes," $0=$ "No"). We found that having watched the documentary did not have a significant impact on any of the outcome variables (information gathering: $H(1)=.037, p=.847$; information exchanging: $H(1)=.047, p=.828$; information promoting: $H(1)=.803, p=.370)$.

To test $\mathrm{H} 2$ regarding the mediation effect of negative affect, we employed the approach of Hayes [2009] and used the PROCESS macro for SPSS. In the present study, statistical significance of the mediation effect was tested using a non-parametric bootstrapping approach with 10,000 bootstrap samples. This approach, unlike the Sobel test of indirect effects [1982], is suitable for use with small samples and does not require any distributional assumptions [Preacher and Hayes, 2004]. Using a non-parametric bootstrapping method, the mediation effect is significant if the upper and lower bounds of the confidence intervals do not contain zero [Efron and Tibshirani, 1993].

\section{Main treatment effects}

Our hypothesized main treatment effects focused on differences between authoritative versus anonymous sources in predicting information-related behavioral intentions. Means for each treatment groups on these outcome variables prior to residualization are reported in Table 1.

Table 1. Descriptive statistics for outcome and mediating variables by treatment group.

\begin{tabular}{|c|c|c|c|c|c|}
\hline & & $\begin{array}{l}\text { Information } \\
\text { gathering }\end{array}$ & $\begin{array}{l}\text { Information } \\
\text { exchanging }\end{array}$ & $\begin{array}{l}\text { Information } \\
\text { promoting }\end{array}$ & $\begin{array}{c}\text { Negative } \\
\text { affect }\end{array}$ \\
\hline \multirow{2}{*}{ Politician lecture $(N=74)$} & Mean & 3.96 & 4.30 & 3.76 & 4.45 \\
\hline & $S D$ & 1.47 & 1.24 & 1.46 & 1.03 \\
\hline \multirow{2}{*}{ Scientist lecture $(N=71)$} & Mean & 3.54 & 4.01 & 3.81 & 4.42 \\
\hline & $S D$ & 1.39 & 1.43 & 1.36 & 1.07 \\
\hline \multirow{2}{*}{ Scientist interview $(N=68)$} & Mean & 3.72 & 3.68 & 3.40 & 3.92 \\
\hline & $S D$ & 1.61 & 1.58 & 1.52 & 1.33 \\
\hline \multirow{2}{*}{ Anonymous narrator $(N=61)$} & Mean & 3.25 & 3.48 & 3.11 & 3.94 \\
\hline & $S D$ & 1.66 & 1.77 & 1.77 & 1.41 \\
\hline
\end{tabular}

H1a postulated that respondents exposed to information presented by an authoritative source will be more likely to gather information compared to those exposed to information presented by an anonymous source. The results of the Kruskal-Wallis test $(H(3)=7.37, p=.061)$ show no significant differences in the likelihood of engaging in information gathering between all four versions of the stimulus.

$\mathrm{H} 1 \mathrm{~b}$ posited group differences in relation to the participants' intention to engage in information exchanging. Specifically, we postulated that those exposed to authoritative sources would be more likely to express intentions to exchange information than those exposed to an anonymous source. We found partial support for $\mathrm{H} 1 \mathrm{~b}(H(3)=10.3, p=.016)$. Pairwise comparisons between the treatments 
revealed significant differences between respondents in the politician lecture and anonymous narrator conditions ( $p=.018, r=.179$ ). Respondents who viewed the politician lecture clip scored higher on the scale of intention to engage in information exchanging relative to those who viewed the clip with the anonymous narrator.

We expected an effect of authoritative information sources on subsequent promotion of information with others (H1c). The result of the Kruskal-Wallis test was significant $(H(3)=9.20, p=.027)$, but after applying the Bonferroni correction for multiple tests, pairwise comparisons failed to reveal significant differences between groups.

\section{Source type and setting effects}

RQ1 focused on possible differential effects by various authoritative sources, specifically experts (scientists) and celebrities (politicians). We did not find statistically significant differences between sources in terms of their ability to affect people's intention to engage in information-related behaviors about global climate change. In other words, information presented by either a politician or a scientist exerted the same impact on people's intentions to gather, exchange, and promote information. As described above, the only significant difference was observed in intention to engage in information exchanging between respondents exposed to a politician and an anonymous narrator.

RQ2 focused on exploring the effects of the context of the video, i.e., whether the source was giving a lecture in an auditorium setting or sitting in an office giving an interview. We did not find any significant effects of communication context (lecture vs. interview) on information-related behavioral intentions. The results of the Kruskal-Wallis tests between communication context conditions are the same as those described for the main treatment effects.

\section{Mediation effect}

$\mathrm{H} 2$ postulated that the effect of information sources on subsequent behavioral changes would be mediated by the negative emotion aroused by the different source types. While mediation analysis can be conducted even if there is no significant relationship between two variables, we opted to perform this analysis only for pairwise comparisons that exhibited significant differences in the interest of parsimony and as a preliminary analysis. Therefore, we only tested the mediating effect of negative affect on intention to exchange information among respondents in the politician lecture $(N=74)$ and anonymous narrator $(N=61)$ treatments. The results of the PROCESS model are reported in Table 2.

The non-parametric bootstrapping approach used to test the indirect effect of source type on information exchanging intention resulted in a point estimate of .271. The lower and upper bounds of the 95 percent confidence interval were .051 and .600 , respectively. As the bounds of the confidence interval do not contain zero, this is indicative of a significant mediation effect [Efron and Tibshirani, 1993].

The total effect of viewing the politician lecture condition compared to the anonymous narrator, denoted by $c$ (Figure 1 ), was positive and significant $(B=.82$, 
Table 2. Model coefficients for the mediating effect of negative affect on information exchanging $(N=135)$.

\begin{tabular}{|rcccccc|}
\hline & \multicolumn{3}{c}{ Negative affect } & \multicolumn{3}{c|}{ Information exchanging } \\
\cline { 2 - 7 } & $\mathrm{B}$ & $\mathrm{SE}$ & $\mathrm{p}$ & $\mathrm{B}$ & $\mathrm{SE}$ & $\mathrm{p}$ \\
\hline Source type (politician lecture = high) & 0.512 & 0.211 & 0.016 & 0.574 & 0.244 & 0.020 \\
Negative affect & - & - & - & 0.464 & 0.098 & $\leq .001$ \\
Constant & 3.939 & 0.156 & $\leq .001$ & -2.221 & 0.425 & $\leq .001$ \\
& \multicolumn{3}{c}{$R^{2}=.043$} & \multicolumn{3}{c}{$R^{2}=.205$} \\
& $F(1,133)=5.911, p=.016$ & $F(2,132)=16.993, p \leq .001$ \\
\hline
\end{tabular}

$S E=.26, p=.002)$. In the mediated model, the direct effect of viewing the different documentary clips, denoted by $c^{\prime}$ (Figure 1 ), was positively associated with negative affect $(B=.55, S E=.24, p=.024)$. In this model predicting respondents' intention to exchange information, negative affect functioned as a mediator; the independent variable was positively related to negative affect $(B=.51, S E=.21, p=.016)$, which, in turn, was positively related to the outcome variable $(B=.53, S E=.10, p \leq .001)$. In other words, respondents exposed to a politician, compared to an anonymous narrator, experienced greater negative affect after viewing the documentary clip. In turn, negative affect was significantly and positively related to intention to exchange information. Overall, this result provides some support for $\mathrm{H} 2$.

\section{(A) Total Effect}

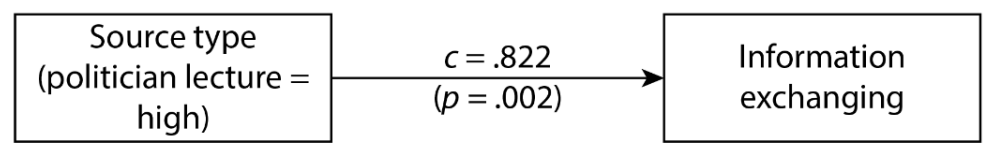

(B) Direct and Indirect Effects

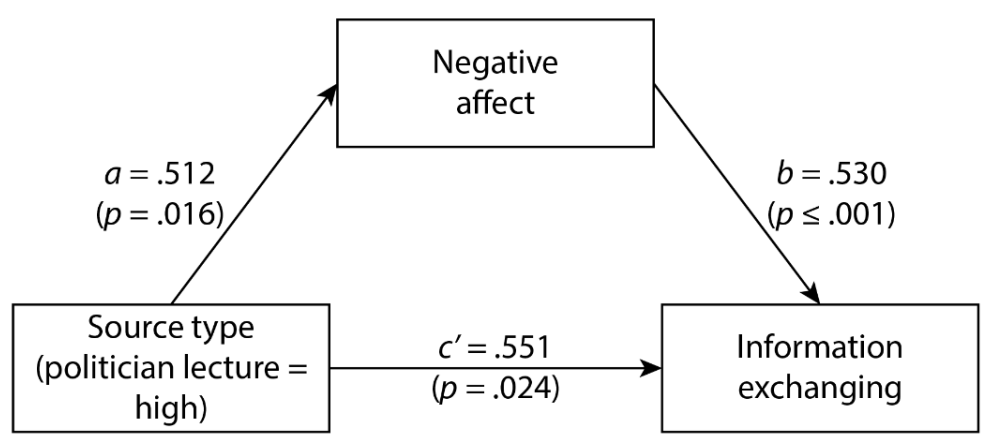

Figure 1. Unstandardized regression coefficients showing direct (A) and indirect (B) effects of source type on information exchanging with negative affect as a mediator. The direct effect is calculated using $c=c^{\prime}+a b$. 
Our study focused on the type of source and communication context of a documentary film about climate change and their potential impacts on information-related behavioral intentions among the film's viewers. The results of our experiment suggest that some authoritative sources - compared to anonymous narrators - can have a significant impact on behavioral intentions. Respondents who viewed a politician compared to an anonymous source reported they were more likely to engage in information exchanging behaviors. Additionally, affective responses to the documentary film clip mediated the relationship between source type and behavioral intentions. Of course, we are wary of drawing broad conclusions based on a single preliminary experiment that employed a student sample. Thus, prior to discussing the relevance of these results for communication theory and our understanding of the effects of documentary films, we address the limitations of our study.

First, as a case study, these results can only be suggestive; our design only allowed us to use a short segment from one documentary film. We specifically chose a segment from on An Inconvenient Truth for several reasons: it was financially successful and featured a novel approach to presenting scientific information through a lecture format. More importantly, however, much of the commentary of the film's widespread success at encouraging public engagement has been based on anecdotal evidence. Our results provide some empirical support for these assertions and we discuss these implications further below.

It should also be noted that our experiment was not a full factorial design. Specifically, we were unable to film a version of our clip with Al Gore seated in an office like our scientist (politician interview) and did not have a control condition. This limits the power of the model; specifically, we are unable to isolate that the documentary alone caused respondents' behavioral intentions. However, the differences between conditions remain significant, which provide preliminary insights into how source attributes can be used as heuristic cues that may influence viewers' intentions related to information. As a result, we are able to make tentative inferences that provide a framework on which future research can build.

As alluded to earlier, a third limitation that could be pointed out is that of our sample, both in terms of size and nature. Our sample size is relatively small and consisted of undergraduate students at two large Midwestern universities. The only concern about college students (or any other population) in the context of experimental research is the question if they are too homogenous a group to produce enough variation to detect effects. More importantly, if college students show less variation than the general population for some key variables, some of the relationships we find in randomized experiments with student groups are actually attenuated compared to what we would find for the general population. In other words, we would be finding even stronger relationships if we were to use samples drawn from the general population.

That these data were collected in 2008 may also be limitation for some. Yet, the mechanisms by which source attributes may function as heuristics are unlikely to change and we intend this study to be a preliminary examination of science documentaries that spurs future work. Scholarship should build on our findings and examine the effects of other sources of information in environmental documentaries on public engagement. For example, recent research has shown that 
trust in communicators can be a reflection people's religious values [Brewer and Ley, 2013; Cacciatore et al., 2018]. How would a religious leader as a source of information in a documentary feature film compare to a scientist or politician? Research that seeks to answer questions such as this will likely yield both theoretical and practical insights that can benefit the scientific endeavor. While we controlled for political ideology in our analyses due to our small sample size, studies with large nationally representative samples can test the moderating effects of individual characteristics on the persuasive effect of heuristic cues embedded in science documentaries.

\section{Attributes of documentary films and their effects}

Building on a foundation in the persuasion literature, our study provided a rationale for exploring the impacts of documentary films on viewers' attitudes. Our results revealed that source type is an important heuristic to consider when communicating about climate change. Most clearly, our experiment provides evidence that, compared to some authoritative sources (politicians), anonymous sources such as narrators are relatively ineffective at encouraging intentions to engage in various behaviors related to information in the film. This result may not be surprising. After all, the use of spokespersons in persuasive messages has a long history, especially in marketing and advertising. This result does, however, have practical implications for science communicators. Indeed, the traditional approach of presenting information in science documentaries with an anonymous narrator appears to be the least effective way to engage audiences with the information.

That we found no significant difference between the scientist and politician conditions is somewhat surprising as people tend to trust scientists more than governmental agencies or their representatives Brewer and Ley [e.g., 2013]. However, a recent study conceptualized scientists and President Obama as formal communicators and found that people who trust these sources tend to perceive climate solutions to be effective [Sleeth-Keppler, Perkowitz and Speiser, 2017]. It may be, therefore, that respondents did not make a distinction between a scientist and $\mathrm{Al}$ Gore, a notorious politician whose position on climate change is clear. In this case, Al Gore's celebrity status and his position on climate change may have caused viewers to perceive him as an expert on the issue.

If having a spokesperson is crucial for communicating science, what impact can the choice of spokesperson have? For An Inconvenient Truth, commentators have suggested that an explicitly political informant such as Al Gore undermines the film's message [Nisbet, 2009]. Republicans and conservatives, for example, might be unwilling both to see the film and to accept its information, a reaction that would exacerbate the existing partisan divide in the U.S. on the issue [Rainie and Funk, 2015]. To investigate this possibility, we postulated that there might be different effects for a scientist, rather than a politician, in presenting this information. Surprisingly, we found no evidence of such differential effects from different types of authoritative sources, despite including explicit labels "politician" and "scientist" for the speaker in the respective versions of our stimulus. Instead, the persuasive impact of the film was only apparent among those who watched the politician deliver information about climate change compared to an anonymous narrator. Moreover, of the three outcomes, only intention to exchange information was impacted by watching the clip with the politician. 
While this differential effect supports $\mathrm{H} 2$ and provides some answers to our two research questions (i.e., type of authoritative source and setting matter relatively little with regards to information-related behavioral intentions), they do not provide much insight into how this effect came about. To understand the process by which the film clip influenced intention to exchange information, we turn to the results of our mediation hypothesis.

\section{Sources, contexts, and affective responses}

As with the previous results, only the clip of the film featuring a politician in a lecture setting resulted in significantly greater levels of negative affect. Moreover, negative affect only significantly mediated the relationship predicting intention to exchange information. Thus, greater negative feelings of anxiety, fear, anger, or some combination of these emotions regarding the information from the film might increase the likelihood that a viewer will share the information with others. In other words, a negative affective state appears to be a sufficient condition for engaging in information exchange about climate change, but not to gather more information or persuade others.

While our research implies that negative affect can encourage people to exchange information, previous work has shown that such frames can be counter-productive to engaging people with this issue [O'Neill and Nicholson-Cole, 2009]. We posit that this contradiction is broadly related to the complexity of climate change. Climate change is not a uniform issue and, as other studies have noted [Lorenzoni, Nicholson-Cole and Whitmarsh, 2007; O'Neill and Nicholson-Cole, 2009], if high fear- or shock-inducing negative frames used in climate communication are distant and unrelatable, then people are unlikely to engage with the issue. Moreover, our study measured information exchanging intention, which is a relatively low effort form of engagement with this issue. It may be that more active forms of engagement are discouraged by strong negative emotions in ways discussed in the extant literature.

Our results point to at least two implications for future research. First, studying the effects of documentary films should receive more attention from communication researchers. Understanding the impacts of these films - and especially those explicitly aimed at public engagement - will inform our current understanding of the societal-level importance of the issues that they make salient. A research focus on these films will complement our extensive understanding of the effects of news coverage, much like the study of political cartoons [e.g., Gamson and Modigliani, 1989]. Second, our theoretical framework provides a starting point for investigations into the attributes of films such as sources and contexts. Our conceptualizations of these attributes can only be interpreted as a preliminary, but promising, foundation on which future research can build.

Beyond these implications for communication research, this study also directs our attention to current methods of communicating science in society. Journalists have bemoaned the decline the science journalism as a profession [e.g., Mooney, 2008], much like media scholars have bemoaned the inability of some scientists to communicate their work effectively [e.g., Nisbet and Scheufele, 2007]. Our case study of An Inconvenient Truth points toward documentary films as one possible avenue for pursuing alternatives to the deficient status quo. 
Acknowledgments This research was supported by a grant from Greater Milwaukee Foundation/Journal Foundation. The authors would like to acknowledge Tsung-Jen Shih (National Chengchi University) for his contributions to the project.

Appendix A. Transcript of stimuli
Antarctica. The largest mass of ice on the planet by far. A friend of mine said in 1978, "If you see the breakup of ice shelves along the Antarctic peninsula, watch out, because that should be seen as an alarm bell for global warming."

But I want to focus on West Antarctica. Because it illustrates two factors about land-based ice and sea-based ice. It's a little of both. It's propped up on tops of islands, but the ocean comes up underneath it. So, as the ocean gets warmer, it has an impact on it. If this were to go, sea level worldwide would go up 20 feet.

They've measured disturbing changes on the underside of this ice sheet. It's considered relatively more stable however than another big body of ice that's roughly the same size. Greenland would also raise sea level almost 20 feet if it went. A friend of mine just brought back some pictures of what's going on in Greenland right now. Dramatic changes.

These are the same kinds of pools that formed here on this ice shelf in Antarctica. And the scientists thought that when that water seeped back into the ice, it would just refreeze. But they found out that actually what happens is that it just keeps on going, it tunnels to the bottom. And makes the ice like Swiss cheese.

This shows what happens to the crevasses and when lakes form they create what are called moulins. The water goes down to the bottom and it lubricates where the ice meets the bedrock. You see these people here for scale? This is not on the edge of Greenland; this is in the middle of the ice mass. This is a massive rushing torrent of fresh melt water tunneling straight down through the Greenland ice to the bedrock below.

Now, to some extent, there has always been seasonal melting and moulins have formed in the past but not like now. In 1992 they measured this amount of melting in Greenland. Ten years later, this is what happened. And here's the melting from 2005

If Greenland broke up and melted, or if half of Greenland and half of West Antarctica broke up and melted, this is what would happen to the sea level in Florida. This is what would happen to San Francisco Bay. A lot of people live in these areas.

The Netherlands, one of the low countries. Absolutely devastating. The area around Beijing, it's home to tens of millions of people. Even worse in the area around Shanghai. There are 40 million people. Worse still, Calcutta, and to the east Bangladesh, the area covered includes 60 million people. Think of the impact of a couple hundred thousand refugees when they're displaced by an environmental event. And then imagine of the impact of a hundred million or more. 
Ajzen, I. (1991). 'The theory of planned behavior'. Organizational Behavior and Human Decision Processes 50 (2), pp. 179-211. https://doi.org/10.1016/0749-5978(91)90020-T.

Ajzen, I. and Fishbein, M. (1970). 'The prediction of behavior from attitudinal and normative variables'. Journal of Experimental Social Psychology 6 (4), pp. 466-487. https://doi.org/10.1016/0022-1031(70)90057-0.

Balasubramanian, S. K. (1994). ‘Beyond Advertising and Publicity: Hybrid Messages and Public Policy Issues'. Journal of Advertising 23 (4), pp. 29-46. https://doi.org/10.1080/00913367.1943.10673457.

Bartlett, M. (2009). 'Representations of the apocalypse: Debating the merits of "An Inconvenient Truth" and "The Great Global Warming Swindle"'. Australian Screen Education 53, pp. 34-41.

Birnbaum, M. H. and Stegner, S. E. (1979). 'Source credibility in social judgment: Bias, expertise, and the judge's point of view'. Journal of Personality and Social Psychology 37 (1), pp. 48-74. https://doi.org/10.1037/0022-3514.37.1.48.

Biswas, D., Biswas, A. and Das, N. (2006). 'The Differential Effects of Celebrity and Expert Endorsements on Consumer Risk Perceptions. The Role of Consumer Knowledge, Perceived Congruency, and Product Technology Orientation'. Journal of Advertising 35 (2), pp. 17-31. https://doi.org/10.1080/00913367.2006.10639231.

Bower, A. B. (2001). 'Highly Attractive Models in Advertising and the Women Who Loathe Them: The Implications of Negative Affect for Spokesperson Effectiveness'. Journal of Advertising 30 (3), pp. 51-63. https://doi.org/10.1080/00913367.2001.10673645.

Brewer, P. R. and Ley, B. L. (2013). 'Whose Science Do You Believe? Explaining Trust in Sources of Scientific Information About the Environment'. Science Communication 35 (1), pp. 115-137. https://doi.org/10.1177/1075547012441691.

Cacciatore, M. A., Browning, N., Scheufele, D. A., Brossard, D., Xenos, M. A. and Corley, E. A. (2018). 'Opposing ends of the spectrum: Exploring trust in scientific and religious authorities'. Public Understanding of Science 27 (1), pp. 11-28. https://doi.org/10.1177/0963662516661090.

Cacioppo, J. T., Petty, R. E., Kao, C. F. and Rodriguez, R. (1986). 'Central and peripheral routes to persuasion: An individual difference perspective'. Journal of Personality and Social Psychology 51 (5), pp. 1032-1043. https://doi.org/10.1037/0022-3514.51.5.1032.

Chaiken, S. (1980). 'Heuristic versus systematic information processing and the use of source versus message cues in persuasion'. Journal of Personality and Social Psychology 39 (5), pp. 752-766. https://doi.org/10.1037/0022-3514.39.5.752.

Chaiken, S., Liberman, A. and Eagly, A. (1989). 'Heuristic and Systematic Information Processing within and beyond the Persuasion Context'. In: Unintended Thought. Ed. by J. Uleman and J. Bargh. New York, NY, U.S.A.: Guilford, pp. 212-252.

Dean, C. (27th September 2007). 'Scientists Feel Miscast in Film on Life's Origin'. The New York Times.

URL: http://www.nytimes.com/2007/09/27/science/27expelled.html.

Dillard, J. P. and Peck, E. (2000). 'Affect and Persuasion. Emotional Responses to Public Service Announcements'. Communication Research 27 (4), pp. 461-495. https://doi.org/10.1177/009365000027004003. 
Eagly, A. H. and Chaiken, S. (1993). The Psychology of Attitudes. Orlando, FL, U.S.A.: Harcourt Brace Jovanovich College Publishers.

Efron, B. and Tibshirani, R. J. (1993). An Introduction to the Bootstrap. Washington, D.C., U.S.A.: Chapman and Hall/CRC. URL: https : //www . crcpress . com/An-In troduction-to-the-Bootstrap/Efron-Tibshirani/p/book/9780412042317.

Ekström, M. (2001). 'Politicians Interviewed on Television News'. Discourse $\mathcal{E}$ Society 12 (5), pp. 563-584. https://doi .org/10.1177/0957926501012005001.

Eveland, W. P. (2003). 'A "Mix of Attributes" Approach to the Study of Media Effects and New Communication Technologies'. Journal of Communication 53 (3), pp.395-410. https://doi.org/10.1111/j.1460-2466.2003.tb02598.x.

Finucane, M. L., Alhakami, A., Slovic, P. and Johnson, S. M. (2000). 'The affect heuristic in judgments of risks and benefits'. Journal of Behavioral Decision Making 13 (1), pp. 1-17. https://doi.org/10.1002/(sici)1099-0771(200001 /03) $13: 1<1:$ : aid-bdm333>3.0.co;2-s.

Fiske, S. T. and Taylor, S. E. (1991). Social cognition. 2nd ed. New York, NY, U.S.A.: McGraw-Hill.

Gamson, W. A. and Modigliani, A. (1989). 'Media Discourse and Public Opinion on Nuclear Power: A Constructionist Approach'. American Journal of Sociology 95 (1), pp. 1-37. URL: http://www . jstor .org/stable/2780405.

George, J. M. and Dane, E. (2016). 'Affect, emotion, and decision making'. Organizational Behavior and Human Decision Processes 136, pp. 47-55. https://doi.org/10.1016/j.obhdp.2016.06.004.

Gerbner, G., Gross, L., Morgan, M. and Signorielli, N. (1982). 'Charting the Mainstream: Television's Contributions to Political Orientations'. Journal of Communication 32 (2), pp. 100-127. https://doi.org/10.1111/j.1460-2466.1982.tb00500.x.

Griffin, R. J., Yang, Z., Huurne, E. ter, Boerner, F., Ortiz, S. and Dunwoody, S. (2008). 'After the Flood'. Science Communication 29 (3), pp. 285-315. https://doi.org/10.1177/1075547007312309.

Hayes, A. F. (2009). 'Beyond Baron and Kenny: Statistical Mediation Analysis in the New Millennium'. Communication Monographs 76 (4), pp. 408-420. https://doi.org/10.1080/03637750903310360.

Horai, J., Naccari, N. and Fatoullah, E. (1974). 'The Effects of Expertise and Physical Attractiveness Upon Opinion Agreement and Liking'. Sociometry 37 (4), pp. 601-606. https://doi.org/10.2307/2786431.

Jacobsen, G. D. (2011). 'The Al Gore effect: An Inconvenient Truth and voluntary carbon offsets'. Journal of Environmental Economics and Management 61 (1), pp. 67-78. https://doi.org/10.1016/j.jeem.2010.08.002.

Kahneman, D. (2011). Thinking, fast and slow. New York, NY, U.S.A.: Farrar, Straus and Giroux.

Kahneman, D., Slovic, P. and Tversky, A., eds. (1982). Judgment under uncertainty: Heuristics and biases. Cambridge, U.K.: Cambridge University Press. https://doi.org/10.1017/cbo9780511809477.

Kruskal, W. H. and Wallis, W. A. (1952). 'Use of Ranks in One-Criterion Variance Analysis'. Journal of the American Statistical Association 47 (260), pp. 583-621. https://doi.org/10.1080/01621459.1952.10483441.

Leiserowitz, A. A. (2004). 'Day After Tomorrow: Study of Climate Change Risk Perception'. Environment: Science and Policy for Sustainable Development 46 (9), pp. 22-39. https://doi.org/10.1080/00139150409603663. 
Lerner, J. S., Li, Y., Valdesolo, P. and Kassam, K. S. (2015). 'Emotion and Decision Making'. Annual Review of Psychology 66 (1), pp. 799-823.

https://doi.org/10.1146/annurev-psych-010213-115043.

Lin, S.-J. (2013). ‘Perceived Impact of a Documentary Film. An investigation of the first-person effect and its implications for environmental issues'. Science Communication 35 (6), pp. 708-733. https://doi.org/10.1177/1075547013478204.

Little, A. G. (7th March 2007). A chat with Inconvenient Truth co-producer and Hollywood bigwig Lawrence Bender. URL: http://grist.org/article/bender/ (visited on 16th September 2016).

Löfgren, $\AA$. and Nordblom, K. (2010). 'Attitudes towards $\mathrm{CO}_{2}$ taxation - is there an Al Gore effect?' Applied Economics Letters 17 (9), pp. 845-848. https://doi.org/10.1080/13504850802584849.

Lorenzoni, I., Nicholson-Cole, S. and Whitmarsh, L. (2007). 'Barriers perceived to engaging with climate change among the UK public and their policy implications'. Global Environmental Change 17 (3-4), pp. 445-459. https://doi.org/10.1016/j.gloenvcha.2007.01.004.

Manzo, K. (2017). 'The usefulness of climate change films'. Geoforum 84, pp. 88-94. https://doi.org/10.1016/j.geoforum.2017.06.006.

McCracken, G. (1989). 'Who is the Celebrity Endorser? Cultural Foundations of the Endorsement Process'. Journal of Consumer Research 16 (3), pp. 310-321. https://doi.org/10.1086/209217.

Mooney, C. (29th October 2008). The Science Writer's Lament: The Missing Section in Your Daily Paper.

URL: https://scienceprogress . org/2008/10/the-science-writers-lament/ (visited on 21st September 2016).

Moyer-Gusé, E. (2008). 'Toward a Theory of Entertainment Persuasion: Explaining the Persuasive Effects of Entertainment-Education Messages'. Communication Theory 18 (3), pp. 407-425. https://doi.org/10.1111/j.1468-2885.2008.00328.x.

Moyer-Gusé, E., Jain, P. and Chung, A. H. (2012). 'Reinforcement or Reactance? Examining the Effect of an Explicit Persuasive Appeal Following an Entertainment-Education Narrative'. Journal of Communication 62 (6), pp. 1010-1027. https://doi.org/10.1111/j.1460-2466.2012.01680.x.

Moyer-Gusé, E. and Nabi, R. L. (2010). 'Explaining the Effects of Narrative in an Entertainment Television Program: Overcoming Resistance to Persuasion'. Human Communication Research 36 (1), pp. 26-52. https://doi.org/10.1111/j.1468-2958.2009.01367.x.

Mutz, D. C. and Nir, L. (2010). 'Not Necessarily the News: Does Fictional Television Influence Real-World Policy Preferences?' Mass Communication and Society 13 (2), pp. 196-217. https://doi.org/10.1080/15205430902813856.

Nabi, R. L. and Hendriks, A. (2003). 'The Persuasive Effect of Host and Audience Reaction Shots in Television Talk Shows'. Journal of Communication 53 (3), pp. 527-543. https://doi.org/10.1111/j.1460-2466.2003.tb02606.x.

Newhagen, J. E. (1998). 'TV news images that induce anger, fear, and disgust: Effects on approach-avoidance and memory'. Journal of Broadcasting $\mathcal{E}$ Electronic Media 42 (2), pp. 265-276. https: //doi.org/10.1080/08838159809364448.

Nisbet, M. C. (2009). 'Communicating Climate Change: Why Frames Matter for Public Engagement'. Environment: Science and Policy for Sustainable Development 51 (2), pp. 12-23. https://doi.org/10.3200/ENVT.51.2.12-23. 
Nisbet, M. C. and Scheufele, D. A. (1st October 2007). 'The Future of Public Engagement'. The Scientist, pp. 38-44.

URL: https://www the-scientist.com/?articles.view/articleNo/25447/ti tle/The-Future-of-Public-Engagement/.

Olson, J. M. (1992). 'Self-perception of humor: Evidence for discounting and augmentation effects'. Journal of Personality and Social Psychology 62 (3), pp.369-377. https://doi.org/10.1037/0022-3514.62.3.369.

O'Neill, S. and Nicholson-Cole, S. (2009). "“Fear Won't Do It”. Promoting positive engagement with climate change through visual and iconic representations'. Science Communication 30 (3), pp. 355-379. https://doi.org/10.1177/1075547008329201.

Petty, R. E. and Cacioppo, J. T. (1986). Communication and persuasion: Central and peripheral routes to attitude change. New York, NY, U.S.A.: Springer-Verlag. https://doi.org/10.1007/978-1-4612-4964-1.

Petty, R. E., Cacioppo, J. T. and Schumann, D. (1983). 'Central and Peripheral Routes to Advertising Effectiveness: The Moderating Role of Involvement'. Journal of Consumer Research 10 (2), pp. 135-146. https: / / doi .org/10.1086/208954.

Pouliot, L. and Cowen, P. S. (2007). 'Does Perceived Realism Really Matter in Media Effects?' Media Psychology 9 (2), pp. 241-259. https://doi.org/10.1080/15213260701285819.

Preacher, K. J. and Hayes, A. F. (2004). 'SPSS and SAS procedures for estimating indirect effects in simple mediation models'. Behavior Research Methods, Instruments, $\mathcal{E}$ Computers 36 (4), pp. 717-731. https://doi.org/10.3758/bf03206553.

Rainie, L. and Funk, C. (12th February 2015). 'How Different Groups Think about Scientific Issues'. Pew Research Center. URL: http://www . pewinternet. org/2015 /02/12/how-different-groups-think-about-scientific-issues/.

Rojas, H., Shah, D. V., Cho, J., Schmierbach, M., Keum, H. and Gil-De-Zuniga, H. (2005). 'Media Dialogue: Perceiving and Addressing Community Problems'. Mass Communication and Society 8 (2), pp. 93-110. https://doi.org/10.1207/s15327825mcs0802_2.

Scherer, K. R. (2005). 'What are emotions? And how can they be measured?' Social Science Information 44 (4), pp. 695-729. https://doi.org/10.1177/0539018405058216.

Shapiro, S. S. and Wilk, M. B. (1965). 'An analysis of variance test for normality (complete samples)'. Biometrika 52 (3-4), pp. 591-611. https://doi.org/10.1093/biomet/52.3-4.591.

Slater, M. D. and Rouner, D. (2002). 'Entertainment-Education and Elaboration Likelihood: Understanding the Processing of Narrative Persuasion'. Communication Theory 12 (2), pp. 173-191. https://doi.org/10.1111/j.1468-2885.2002.tb00265.x.

Slater, M. D., Rouner, D. and Long, M. (2006). 'Television Dramas and Support for Controversial Public Policies: Effects and Mechanisms'. Journal of Communication 56 (2), pp. 235-252. https://doi.org/10.1111/j.1460-2466.2006.00017.x.

Sleeth-Keppler, D., Perkowitz, R. and Speiser, M. (2017). 'It's a Matter of Trust: American Judgments of the Credibility of Informal Communicators on Solutions to Climate Change'. Environmental Communication 11 (1), pp. 17-40. https://doi.org/10.1080/17524032.2015.1062790. 
Slovic, P., Finucane, M. L., Peters, E. and MacGregor, D. G. (2002). 'Rational actors or rational fools: implications of the affect heuristic for behavioral economics'. The Journal of Socio-Economics 31 (4), pp. 329-342. https://doi.org/10.1016/s1053-5357(02)00174-9.

- (2004). 'Risk as Analysis and Risk as Feelings: Some Thoughts about Affect, Reason, Risk, and Rationality'. Risk Analysis 24 (2), pp. 311-322. https://doi.org/10.1111/j.0272-4332.2004.00433.x.

Sobel, M. E. (1982). 'Asymptotic Confidence Intervals for Indirect Effects in Structural Equation Models'. Sociological Methodology 13, p. 290. https://doi.org/10.2307/270723.

Stanovich, K. E. and West, R. F. (2000). 'Individual differences in reasoning: Implications for the rationality debate?' Behavioral and Brain Sciences 23 (5), pp. 645-665. https://doi.org/10.1017/s0140525x00003435.

Stroud, N. J. (2007). 'Media Effects, Selective Exposure, andFahrenheit 9/11'. Political Communication 24 (4), pp. 415-432. https://doi.org/10.1080/10584600701641565.

Till, B. D. and Shimp, T. A. (1998). 'Endorsers in Advertising: The Case of Negative Celebrity Information'. Journal of Advertising 27 (1), pp. 67-82. https://doi.org/10.1080/00913367.1998.10673543.

Trumbo, C. (1996). 'Constructing climate change: claims and frames in US news coverage of an environmental issue'. Public Understanding of Science 5 (3), pp. 269-283. https://doi.org/10.1088/0963-6625/5/3/006.

Tversky, A. and Kahneman, D. (1974). 'Judgment under Uncertainty: Heuristics and Biases'. Science 185 (4157), pp. 1124-1131. https://doi.org/10.1126/science.185.4157.1124.

Valenzuela, S. and Brandão, A. S. (2015). ‘Historical Dramas, Current Political Choices: Analyzing Partisan Selective Exposure With a Docudrama'. Mass Communication and Society 18 (4), pp. 449-470. https://doi.org/10.1080/15205436.2015.1016178.

Watson, D., Clark, L. A. and Tellegen, A. (1988). 'Development and validation of brief measures of positive and negative affect: The PANAS scales'. Journal of Personality and Social Psychology 54 (6), pp. 1063-1070. https://doi.org/10.1037/0022-3514.54.6.1063.

Wilson, E. J. and Sherrell, D. L. (1993). 'Source effects in communication and persuasion research: A meta-analysis of effect size'. Journal of the Academy of Marketing Science 21 (2), pp. 101-112. https://doi .org/10.1007/bf02894421.

Wu, W.-Y., Linn, C. T., Fu, C.-S. and Sukoco, B. M. (2012). 'The Role of Endorsers, Framing, and Rewards on the Effectiveness of Dietary Supplement Advertisements'. Journal of Health Communication 17 (1), pp. 54-75. https://doi.org/10.1080/10810730.2011.585689.

Authors

Sara K. Yeo (Ph.D., University of Wisconsin-Madison) is an Assistant Professor in the Department of Communication and an affiliate with the Global Change and Sustainability Center and the Environmental Humanities Program at the University of Utah. Her research interests include science communication, public opinion of STEM issues, and information seeking and processing. Dr. Yeo is trained as a bench and field scientist and holds a M.S. in Oceanography from the University of Hawaii at Manoa. E-mail: sara.yeo@utah.edu. 
Andrew R. Binder (Ph.D., University of Wisconsin-Madison) is an Associate Professor and Director of Graduate Programs in the Department of Communication at North Carolina State University. He conducts research on controversial science topics, including how information about those topics is transmitted through various communication channels and what impact that communication has on risk perception and public understanding of science. E-mail: arbinder@ncsu.edu.

Michael F. Dahlstrom (Ph.D., University of Wisconsin-Madison) is an Associate Professor in the Greenlee School of Journalism and Communication at Iowa State University. His research focuses on how storytelling impacts the communication of science to non-expert audiences and the contrasting ethical considerations involved. His work in these areas extend across diverse scientific contexts, including risk, health, agricultural and environmental communication.

E-mail: mfd@iastate.edu.

Dominique Brossard (Ph.D., Cornell University) is Professor and Chair in the Department of Life Sciences Communication and an affiliate at the Robert \& Jean Holtz Center for Science and Technology Studies, the Center for Global Studies, and the Morgridge Institute for Research at the University of Wisconsin-Madison. Her research agenda focuses on the intersection between science, media, and policy. E-mail: dbrossard@wisc.edu.

\section{How to cite}

Yeo, S. K., Binder, A. R., Dahlstrom, M. F. and Brossard, D. (2018). 'An inconvenient source? Attributes of science documentaries and their effects on information-related behavioral intentions'. JCOM 17 (02), A07. https://doi.org/10.22323/2.17020207. 